\title{
Internet, el nuevo canal para la información del tiempo
}

\author{
María Luisa SÁnchez CALERo \\ Universidad Complutense de Madrid \\ mlusaca@ccinf.ucm.es \\ Jorge PARDINA HORNO \\ Universidad Complutense de Madrid \\ jphzgz@gmail.com
}

Recibido: 30/01/2011

Aceptado: 22/06/2011

\begin{abstract}
Resumen
Analizar las tendencias y posicionamiento que adquiere la información meteorológica en los portales específicos y en la prensa digital ha sido el objeto de una investigación amplia y extensa. Pero este artículo solo muestra una parte de la misma donde se resaltan las características de nueve portales meteorológicos con fuerte presencia en las webs españolas de Meteorología donde se han analizado aspectos como: Lenguaje y vocabulario utilizado, Las fuentes consultadas, La organización de los contenidos, Los sistemas de búsqueda, El material gráfico, Los sistemas de alertas, La información divulgativa y Las posibilidades de interacción de los usuarios. Lo que ha requerido metodológicamente diseñar un cuestionario y enviar 400 encuestas destinadas a captar el perfil de los usuarios que consultan esta información en las webs. Además de analizar 30 páginas Web y portales españoles públicos y privados vinculados a aspectos deportivos o de ocio en los que existe un apartado destacado sobre la información Meteorológica. Y por último, la identificación y estudio de 9 portales específicos de información meteorológica que se identificaron como los más referenciados en el estudio previo de las webs relacionadas con aspectos de ocio, deporte y actividades al aire libre.
\end{abstract}

Palabras clave: Portales de información meteorológica, sistemas de alertas, websites, pronóstico del tiempo, AEMET.

\section{New Weather channel "Internet"}

\begin{abstract}
Analyse trends and positioning that acquires the weather in digital press and specific portals has undergone a comprehensive and extensive research. But this single article shows a part of it where highlighting the characteristics of nine weather portals with strong presence in the Spanish webs of meteorology where aspects have been analysed as: language and vocabulary used, the sources consulted, the organization of the contents, search, graphic material, alert systems, the communicating systems and user interaction possibilities. It has required methodologically designing a questionnaire and send 400 surveys aimed to capture the profile of users consulting this information on the websites. Addition to analysing 30 websites and public and private Spanish portals linked to sports areas or leisure there a section highlighted on the meteorological information. And finally, the identification and study of 9 portals specific meteorological information were identified as referenced in the previous study of the related web sites with aspects of leisure, sports and outdoor activities.
\end{abstract}

Keywords: Weather portals meteorology, alert systems, web sites, weather forecast, AEMET.

\section{Referencia normalizada}

SÁNCHEZ CALERO, María Luisa y PARDINA HORNO, Jorge (2011): "Internet, el nuevo canal para la información del tiempo". Estudios sobre el mensaje periodístico, vol. 17, núm. 2, págs.: 615-630. Madrid, Servicio de Publicaciones de la Universidad Complutense.

${ }^{1}$ Este artículo se basa en una parte de la investigación presentada como Trabajo Fin de Master en el Máster Oficial de Periodismo de la UCM, en septiembre de 2010. El material empleado ha sido específicamente ampliado y actualizado para esta edición. 
Sumario: 1. Introducción. 2. Nuevos intereses, nuevos canales, nuevos contenidos de la Información Meteorológica en la web. 3. Lenguaje y vocabulario utilizado. 4. Las fuentes consultadas. 5. La organización de los contenidos (secciones y subsecciones). 6. Los sistemas de búsqueda. 7. El material gráfico. 8. Los sistemas de alertas. 9. La divulgación de la información. 10. Las posibilidades de interacción de los usuarios. 11. Conclusiones. 12. Referencias bibliográficas.

\section{Introducción}

Recientes acontecimientos relacionados con fenómenos meteorológicos adversos han puesto de manifiesto la importancia que el tiempo, clima o el agua tienen en la sociedad actual, constituyéndose como elementos de especial importancia que condicionan la vida de las personas y su influencia en el desarrollo socioeconómico y medioambiental. Actualmente es frecuente ver como la Información Meteorológica ocupa las primeras planas de los medios de comunicación adquiriendo cierto protagonismo incluso en los sumarios de apertura de los informativos. El tiempo meteorológico ha sido un fenómeno de gran interés para muchas etapas de la humanidad pero también en nuestros días sigue siendo para muchos sectores de la opinión pública una de las informaciones más solicitadas. Una información que cada vez tiene más seguidores con diferentes intereses y que precisan de canales que se adapten a sus necesidades y prioridades para estar informados de forma rápida y en tiempo real.

En este sentido se hace necesario dar una respuesta informativa que cubra las preocupaciones de estos usuarios en los medios de comunicación. Lo que se traduce en la práctica no sólo en la selección de unos contenidos específicos, sino en el empleo de canales, fuentes y sistemas que permitan mejorar las capacidades de su predicción.

Esta demanda ha constatado la aparición de un nuevo usuario que se siente más identificado y satisfecho ante la consulta de esta información en el entorno digital, bajo la presencia de "websites" privadas e institucionales, que recogen el pronóstico del tiempo bajo la presentación de códigos y contenidos más visibles que facilitan al máximo la percepción y comprensión de los mismos con respuestas y orientaciones a sus propias necesidades. Y en este artículo intentamos recoger las características más generales y procedentes de una investigación más completa que ha basado la investigación en tres pilares fundamentales. El primer análisis responde a la consulta realizada a través de unas 400 encuestas destinadas a averiguar el perfil de los usuarios de la información meteorológica y verificar que porcentaje de ellos se informan del tiempo a través de las diferentes websites.

En una segunda parte se han seleccionado una treintena de páginas Web y portales españoles públicos y privados vinculados a aspectos deportivos u ocio en los que existe un apartado destacado donde informan de la Meteorología de su zona, bien a través de información local o mediante una información adherida a alguna web o portal especializado.

$\mathrm{Y}$ en una tercera parte se han estudiado las características principales de los portales específicos de información meteorológica que se identificaron como los más referenciados en el estudio previo de las webs relacionadas con aspectos de ocio, deporte y actividades al aire libre. Entre ellos destacan www.meteogalicia.es, www.eltiempo.es, www.tutiempo.net, www.windguru.com, www.meteored.com, www.weather.com, www.weatherunderground.com, www.aemet.es, www.duvulgameteo.es.

El objetivo del estudio ha sido señalar los portales que mejor adaptan las características de Internet para presentar la información meteorológica a la opinión pública 
y cuáles son los aspectos más sobresalientes en cada uno de ellos. Se ha convertido objeto del análisis algunos aspectos como los que presenta este artículo donde se exponen en sus diferentes apartados: el lenguaje utilizado y el vocabulario, las fuentes consultadas, la organización de los contenidos por secciones y subsecciones, los sistemas de búsqueda, el material gráfico que incorporan, la utilización de sistemas de alertas, el tratamiento de la información valorando si es más o menos divulgativo, las posibilidades de interacción con los usuarios, la publicidad que insertan o el marco jurídico de la web. Estos elementos corresponden en muchas ocasiones a los principales obstáculos por los que determinadas informaciones no llegan al ciudadano y en este sentido hemos querido descifrarlo para este estudio.

\section{Nuevos intereses, nuevos canales, nuevos contenidos de la Información Mete- orológica en la web}

El incremento, interés y una mayor demanda de información meteorológica por parte de públicos muy diversos justifica en la actualidad un incremento de espacios meteorológicos y una mayor presencia de la información en la red adaptada a las prestaciones y necesidades que demandan los nuevos públicos con nuevas finalidades en su uso y destinada a otros campos de interés.

Por ello esta información reclama una nueva identidad bajo la presencia de otros canales, espacios y formatos adaptados a su nuevo uso en la red con el objeto de presentar de forma rápida y accesible esta información "del tiempo", en tiempo real. Lo que se ha traducido en la aparición de nuevas webs, que trabajan para transmitir con inmediatez, interactividad, elementos multimedia y un lenguaje más adaptado a los nuevos soportes. Y que además apuestan por soluciones eficaces que sean capaces de divulgar de forma correcta y sencilla en los términos adecuados.

La presencia de nuevos canales que están permitiendo una difusión mayor de la información meteorológica como el teléfono móvil ya nos ofrecen datos bajo demanda de los usuarios o la wii que posee un canal meteo y que está siendo distribuido por la empresa japonesa Weather Newsan. Unos datos que nos hace plantearnos como se difunde a la opinión pública la presentación y divulgación de estos datos y el uso que hacen de ellos. Una información que se enfrenta a nuevos cambios y a los hábitos de consumo de nuevas plataformas que generan nuevos modelos de negocios que canalizan esta información hacia modelos más rentables distribuidos por muchas partes del mundo.

\section{Lenguaje y vocabulario utilizado}

El mensaje del tiempo atmosférico en opinión de muchos de los profesionales que informan del tema debe de ajustarse a una serie de características básicas: claridad y concisión, rigurosidad y honestidad marcando las pautas en un mensaje razonado. Conseguir en definitiva que la información se convierta en protagonista y que no sea el aspecto tecnológico el que adquiera mayor importancia que el mapa del tiempo, que debe cumplir una función de explicar visualmente. Esta ciencia meteorológica cuyas dificultades léxicas y conceptuales constituyen uno de los factores principales para la incomprensión de los textos está cada vez más concienciada de la importan- 
cia que tiene entender su mensaje adaptándolo al medio apropiado con el objeto de que el usuario lo comprenda.

En este estudio efectuado a través del análisis de nueve portales específicos de información meteorológica son identificados como los más referenciados en el análisis previo de cincuenta webs españolas de ocio, deporte y actividades al aire libre. Y las webs seleccionadas son las siguientes: www.meteogalicia.es, www.eltiempo.es, www.tutiempo.net, www.windguru.com, www.meteored.com, www.divulgameteo.es, www.weather.com, www.weatherunderground.com y www.aemet.es. El objetivo como ya hemos presentado ha sido determinar, con distintas aproximaciones, cuáles son aquellos que mejor aprovechan las características de Internet para presentar la información meteorológica al público y en qué aspectos destacan cada uno de ellos. En este sentido, hemos analizado el mensaje, lenguaje y vocabulario utilizado con el objeto de conocer la manera en la que la información se transmitía en cada uno de los portales de la muestra. Y con el fin de completar algunos aspectos cualitativos de esta información, imposibles de averiguar mediante el análisis funcional, decidimos también contactar con los responsables de los portales meteorológicos españoles.

Estos portales presentan en sus páginas de inicio bastantes diferencias entre ellos, ya que cada uno evidencia el tema respondiendo a sus características empresariales. Se hace notable, como la mayoría de ellos carecen de textos informativos en su página de inicio encontrándose dominada por otros elementos visuales como la presencia de gráficos, imágenes, iconos, tablas y publicidad exagerada aportando en ocasiones sensación de desorden en algunos portales como en el ejemplo de www.tutiempo.net. Sin embargo en algunos de ellos existe una información detallada y completa a través del "servicio de pago" que incluyen ciertos portales como el americano www.windguru.com ${ }^{2}$ que tras la cuota de 19 euros anuales se puede acceder a los contenidos del portal. Mientras que en otros portales como www.meteogalicia.es, www.meteored .com, www.aemet.es o en ww.eltiempo.es, encontramos en su página de inicio la presencia de textos que incluyen explicación detallada de la información mediante la presencia del resumen de la predicción del día y unas secciones con textos breves y explicación detallada y planificada. Secciones que utilizan un lenguaje adecuado en términos y expresiones fáciles de comprender sin caer en un uso excesivo de tecnicismos y términos científicos además de incluir enlaces donde nos dirigen a una información más específica sobre el tema. Destacar en este sentido, que aunque escasean los textos escritos o se encuentran en secciones secundarias y su presencia en la página de inicio es en casi todos prácticamente irrelevante existen excepciones como la

\footnotetext{
${ }^{2}$ El interés del público estadounidense por la Información Meteorológica se evidenció desde que el New York Times comenzó a presentar impresiones con la predicción alrededor de 1870. Más tarde, tras el regreso de los soldados estadounidenses de los campos de batalla de la Primera Guerra Mundial, se incrementó su presencia en los medios. La mayoría de los diarios empezaron a incluir mapas del tiempo entre sus páginas y poco después la predicción dio el salto a las emisoras de radio. Tras algunas emisiones experimentales en los años 30, en 1941, la cadena WNBC-TV comenzó a ofrecer información meteorológica televisada a los residentes de la ciudad de Nueva York, el pasó a la televisión supuso un éxito. ("Television Weathercasters", BINKLEY, 1999)
} 
sección de "bloguea" escrita por José Antonio MALDONADO director de ww.eltiempo.es. También en la web de la Aemet encontramos secciones, como las noticias o el espacio divulgativo, en los que aparecen textos correctamente escritos, con explicaciones entendibles y útiles. Y en ambos casos se trataba de textos muy breves, con el correspondiente enlace a la información pormenorizada. En algunos otros como www.meteogalicia.es, se observa una observación detallada sobre el ámbito geográfico de influencia. Utilizan un lenguaje específicamente dirigido a un público muy concreto, en este caso el gallego. Es una forma muy directa y clara de empatizar con los usuarios afines al uso de la web e intentar garantizar su fidelidad. En la siguiente tabla podemos observar como solamente se encontraron textos informativos en las páginas iniciales de www.meteogalicia.es y www.aemet.es.

\begin{tabular}{|l|c|c|}
\hline \multicolumn{1}{|c|}{ Webs informativas del tiempo } & $\begin{array}{c}\text { Textos informativos en } \\
\text { la página principal }\end{array}$ & $\begin{array}{c}\text { Total de palabras de } \\
\text { los textos }\end{array}$ \\
\hline www.meteogalicia.es & $\begin{array}{c}1 \\
\text { (resumen de la predicción) }\end{array}$ & 39 \\
\hline www.eltiempo.es & 0 & 0 \\
\hline www-tutiempo.net & 0 & 0 \\
\hline www.windguru.com & 0 & 0 \\
\hline www.meteored.com & 0 & 0 \\
\hline www.weather.com & 0 & 0 \\
\hline www.weatherunderground.com & 0 & 0 \\
\hline www.aemet.es & 4 (resumen de noticias) & 43 \\
\hline
\end{tabular}

\section{Las fuentes consultadas}

En la Información Meteorológica proporcionada en la mayoría de la webs consultadas escasean las fuentes primarias, porque son muy pocos los organismos que tienen los medios técnicos necesarios para convertirse en generadores de información. La mayoría de los portales se dedican principalmente, al tratamiento y presentación de datos mediante la producción de informaciones propias generadas a partir de fuentes primarias. Es decir, se constituyen como paso intermedio para facilitar y adaptar la información de las fuentes primarias a los potenciales usuarios finales, ya sean entidades públicas o privadas, webs similares o personas individuales. Solamente en dos de los nueve portales analizados hemos encontrado que se hace referencia explicita a la fuentes utilizadas, son www.eltiempo.es y www.aemet.es. En www.eltiempo.es, las fuentes son, además de el mismo como observador de contenidos, la compañía Foreca ${ }^{3}$ y en la página de la Agencia Estatal de Meteorología la fuente es ella misma y sus sis-

${ }^{3}$ Foreca es una compañía privada finlandesa fundada en 1996 que se dedica a ofrecer servicios relacionados con la información meteorológica a clientes de todo el mundo. Se definen a sí mismos como pioneros en este tipo de servicios para los medios digitales y manifiestan su especial interés por los últimos avances tecnológicos. Ofrecen todo tipo de soluciones, atractivas visualmente y desde el punto de vista de la interacción de los usuarios, adaptándolas a las necesidades de cada página web. 
temas propios de información. En el resto de los portales no aparecen las fuentes, bien porque se trata de información propia, o bien porque no quieren o no les interesa revelar este dato por algún motivo.

\section{La organización de los contenidos (secciones y subsecciones)}

La organización de los contenidos es esencial para el éxito de una web y por tanto la distribución de sus secciones y subsecciones deben ser claras, representativas, no ambiguas y detallarse de forma ordenada mediante criterios lógicos, con una buena planificación que suele requerir varios ciclos de pruebas y reestructuraciones.

Es importante destacar en este sentido que la calidad y profundidad de todos estos contenidos varían de unos portales a otros, como nos demuestra la presentación de sus páginas y en las informaciones contenidas en ellas. Principalmente se hace notable el contraste entre la seriedad y el rigor de la página de la Aemet, con la manifiesta escasez de medios de otras como www.tutiempo.net o www.meteogalicia.es. En el caso de los más débiles su principal objetivo es la diferenciación, que consiste en encontrar al menos un punto en el que puedan destacar sobre el resto de los competidores. Y, a partir de ahí, intentar captar y mantener a sus usuarios haciendo uso de estas armas. En www.meteogalicia.es está claro por ejemplo que su punto fuerte es la especialización en toda la información meteorológica que detalla aspectos de previsiones en el litoral gallego. En www.windguru.com son, como su propio nombre indica, expertos en la caracterización de los vientos. En www.tutiempo.es potencian la sencillez en la organización y la navegación, cimentada en una cuidada y atractiva presentación visual.

En la presentación de algunos otros portales como www.eltiempo.es, www.tutiempo.net, www.divulgameteo.es o www.meteored.com, optan por la utilización de una barra superior con pestañas para delimitar de una forma muy precisa y visual cuales son las secciones incluidas en su web. Otros, como www.aemet.es, utilizan esta barra en el lateral izquierdo de la página para ubicar los enlaces a las distintas secciones. Otro sistema más clásico pero visualmente efectivo es www.meteogalicia.es que hace uso de los iconos para mostrar las secciones pero aparecen acompañados de un texto aclarativo (en este caso en gallego) para evitar confusiones ya que su significado no es evidente. A veces alguna de estas web peca en la acumulación de elementos gráficos con un diseño poco cohesionado que no acaban de encajar, como demuestra www.weatherunderground.com, lo que provoca una sensación de desorden y desconcierto en el usuario, al tiempo que incomodan la navegación. En cualquier caso, la experiencia demuestra que los portales estadounidenses tienen, por lo general, un aspecto mucho más recargado y complejo que los españoles. Una característica que delata posiblemente el avance y experiencia que nos llevan en la utilización de este tipo de informaciones de servicio. Sus usuarios están más habituados a las consultas y, por tanto, lo que a nosotros nos puede parecer un desorden informativo para ellos puede ser simplemente una aglomeración de datos accesibles de forma rápida y directa.

Podemos apreciar en este estudio que la mayoría de las webs analizadas, dividen sus contenidos en pocas secciones pero bien pensadas, como observamos en www.aemet.es o www.eltiempo.es, en un diseño organizativo que podríamos definir 
como minimalista. Otras, sin embargo, presentan una infinidad de secciones y subsecciones desde la primera pantalla, como en www.windguru.com, que dan una sensación de barroquismo poco recomendable si queremos facilitar la interacción de los usuarios. Por supuesto que la abundancia y variedad de contenidos es un punto positivo en cualquier portal especializado pero hay que saber dosificar su presencia en la pantalla para no fatigar a los internautas.

Podemos encontrar también otras secciones categorizadas como previsibles y compartidas entre distintos portales como predicción, galería de imágenes o fotos, avisos, mapas meteorológicos o foros. Y también, en determinados casos, aparecen otras que pueden resultar sorprendentes, ya que su relación con la Información Meteorológica es más bien tangencial: astronomía y viajes (en www.tutiempo.net), tierra y esquí (en www.meteored.com) o camino de Santiago (en www.meteogalicia.es). Quizás esto se puede tomar como un intento como indicábamos en alguna de ellas aludiendo a esa diferenciación que buscan respecto a la competencia - cada vez más numerosa y potente- pero su presencia no siempre está claramente justificada.

Algunas secciones como los blogs y la interacción de los usuarios a través de fotografías y vídeos están en auge en muchos de los portales analizados. En el caso de www.eltiempo.es, el blog, se convierte en una parte fundamental del portal, es el mecanismo de interacción directa entre el director del portal, José Antonio Maldonado, y los usuarios. No es el único caso ya que en España existen otros portales de información meteorológica con un fuerte carácter personalista como por ejemplo www.divulgameteo.es de José Miguel ViÑas que presenta su espacio dedicado al pronóstico del tiempo solo los fines de semana denominándole así "El tiempo del finde" Los portales estadounidenses analizados son, por el contrario, menos proclives a incluir este tipo de secciones interactivas. Su objetivo es, sobre todo, ofrecer un servicio informativo rápido y preciso. La interacción participativa y creativa de los usuarios requiere un tiempo y un esfuerzo que la mayor parte de los usuarios, al menos eso parece deducirse desde el punto de vista americano, no están dispuestos a realizar. La excepción es www.weatherunderground.com que sí ofrece una sección completísima de blogs y la posibilidad de incluir y comentar fotografías.

\begin{tabular}{|l|c|c|}
\hline \multicolumn{1}{|c|}{ Webs informativas del tiempo } & $\begin{array}{c}\text { Secciones principales } \\
\text { (primer nivel) }\end{array}$ & $\begin{array}{c}\text { Secciones } \\
\text { (segundo nivel) }\end{array}$ \\
\hline www.meteogalicia.es & 5 & $\begin{array}{c}\text { No accesibles desde } \\
\text { menú principal }\end{array}$ \\
\hline www.eltiempo.es & 5 & 5 \\
\hline www-tutiempo.net & 7 & 38 \\
\hline www.windguru.com & 8 & 26 \\
\hline www.meteored.com & 15 & 83 \\
\hline www.weather.com & 5 & $\begin{array}{c}\text { No accesibles desde } \\
\text { menú principal }\end{array}$ \\
\hline www.divulgameteo.es & 9 & 2 \\
\hline www.weatherunderground.com & 7 & 44 \\
\hline www.aemet.es & 7 & 26 \\
\hline
\end{tabular}




\section{Los sistemas de búsqueda}

Una de las herramientas fundamentales en las páginas web, son los sistemas de búsqueda, sobre todo aquellos que alcanzan una determinada dimensión y un cierto nivel de complejidad. Los portales son sitios web que cuentan con un buscador para facilitar al usuario la localización de determinados elementos de una forma rápida y eficaz. En nuestro estudio, solamente www.meteogalicia.es, no contaba con un sistema de búsqueda mientras que el resto ofrecían buscadores más o menos completos que facilitan la localización de contenidos concretos. Entre los sistemas más fáciles encontramos los pertenecientes al www.eltiempo.es, www.divulgameteo.es y www.meteored.es, que consisten en una búsqueda elemental por localidad. Tampoco en www.aemet.es existe la búsqueda avanzada, aunque en este caso se permite buscar libremente por un término que escribe el usuario, lo que supone una flexibilidad algo mayor al poder incluir en el campo de búsqueda cualquier palabra clave -relacionada o no con el ámbito geográfico- que permita un rastreo más refinado.

En otros, por el contrario, se incluyen variados y detallados filtros de búsqueda, y se encuentran ubicados en un lugar preferente dentro de la página principal como en www.windguru.com, que nos permite tomar decisiones para limitar los resultados a unas horas concretas del día, mostrar mapa o no, las actividades deportivas asociadas a la localidad y muchas más opciones. También en www.weatherunderground.com encontramos un sistema muy completo que nos permite buscar por código de aeropuerto, por estaciones meteorológicas personales, en blogs, etcétera. Por lo general, son los portales americanos analizados, quienes incluyen unos sistemas de búsqueda más potentes y precisos. Con esto se desprende que están específicamente diseñados para usuarios más bien experimentados y que precisan de un uso más intensivo de las herramientas de búsqueda.

Aunque no es el sistema más habitual, algunos portales, como www.weather.com o www.tutiempo.net, conectan sus buscadores directamente con el buscador genérico Google. No es muy profesional ni inteligente, desde el punto de vista de la retención y fidelización de los usuarios, que nuestros buscadores conduzcan a páginas externas a la web. Por esa razón, se suelen evitar este tipo de soluciones a no ser que por alguna causa constituyan la única opción viable.

\section{El material gráfico}

Transmitir la Información Meteorológica en los portales utilizando toda clase de material gráfico complementario se hace cada vez más imprescindible y eficaz para los receptores. Las características de esta información compleja en el origen, basada en el tratamiento de una gran cantidad de datos numéricos, sofisticados algoritmos y múltiples estadísticas, se adapta bien a la representación visual. Es por tanto un aspecto que hay que saber aprovecharlo bien porque de ello dependerá en gran medida el éxito de una web de este tipo.

En los portales analizados aparecen numerosos elementos gráficos, que en muchas ocasiones predominan sobre el texto y juegan un papel fundamental en el diseño y presentación de la información. Aunque varía bastante el diseño y estilo presentado en los portales podríamos decir que existen dos categorías, que son por una parte aque- 
llos que optan por un apoyo gráfico simple, minimalista y conceptual, y los que prefieren las imágenes realistas, los máximos detalles y alcanzar una precisión milimétrica en las representaciones. En el primer grupo se incluirían: www.meteogalicia.es, www.eltiempo.es, www.divulgameteo.es o www.tutiempo.net.

En el segundo, www.weather.com, www.weatherunderground.com o www.windguru.com. Por supuesto, también existe el término medio en el caso de la Aemet, por ejemplo, que combina acertadamente los materiales gráficos sencillos con los más complejos y realistas. Además, están muy bien distribuidos por lo que resultan fáciles de localizar por el usuario.

El tipo de diseño visual dependerá, del público objetivo del portal. Si queremos llegar al ciudadano medio, posiblemente, será mejor optar por un diseño simple, sobrio y agradable, como el de www.eltiempo.es. Si por el contrario nos importa más informar a un tipo de usuario muy específico, como por ejemplo todos los aficionados a los deportes marítimos en los que el viento juega un papel fundamental, entonces optaremos por la profundización y el detalle, con mapas más complejos (ver captura de ww.windguru.com). En el caso de que el usuario tipo sea muy variado tendremos que intentar abarcar lo máximo y saber coordinar los dos modelos, como ocurre en la Aemet.

En los últimos tiempos, cada vez es más frecuente que los portales utilicen material gráfico dinámico, en vez de las clásicas imágenes estáticas. Pero de momento, no todos poseen los medios necesarios para incluir y manejar este tipo de sistemas visuales con soltura. Por ejemplo, en www.eltiempo.es, www.tutiempo.net o www.meteored.com siguen predominando las imágenes fijas. En otros, como www.aemet.es o www.weather.com, sí se han asentado las representaciones visuales con progresión dinámica y, gracias a las mejoras en el ancho de banda, se pueden manipular cada día con mayor agilidad en cualquier tipo de dispositivo.

Otro tipo de imágenes que aparecen en todos los portales y se convierten en un elemento básico de la Información Meteorológica son las del satélite que se hacen indispensables hoy en día, incluso si nos dirigimos a un público poco especializado porque se han generalizado gracias a su presencia en la televisión. Así pues, las proporcionadas por el conocido satélite Meteosat son frecuente que aparezcan pero también las de los satélites Goes o NOAA ${ }^{4}$.

Una de las ventajas de la Red, con respecto a otros medios como la televisión, es que el espacio informativo es relativamente mucho más económico. De este modo, se puede incluir una mayor variedad de materiales gráficos especializados, con una información muy localizada, precisa y variada, difícil de obtener en prensa, radio o televisión. Podemos encontrar mapas de vientos, de humedad, de la información de los embalses, de las costas, de rayos, de visibilidad, de la temperatura del agua del mar, etcétera. En Internet, una vez edificados los cimientos, resulta técnicamente asequible añadir nuevos pisos y habitaciones. La escalabilidad, la versatilidad y la flexibili-

${ }^{4} \mathrm{http}: / /$ www.eumetsat.int/Home/index.htm. Página web de la organización europea encargada de la explotación comercial de los satélites meteorológicos. 
dad son propiedades profundamente ligadas a la Red y muy provechosas para los nuevos medios informativos digitales.

Ejemplo de mapa complejo de predicción del 28/01/2011. Fuente: windguru.com

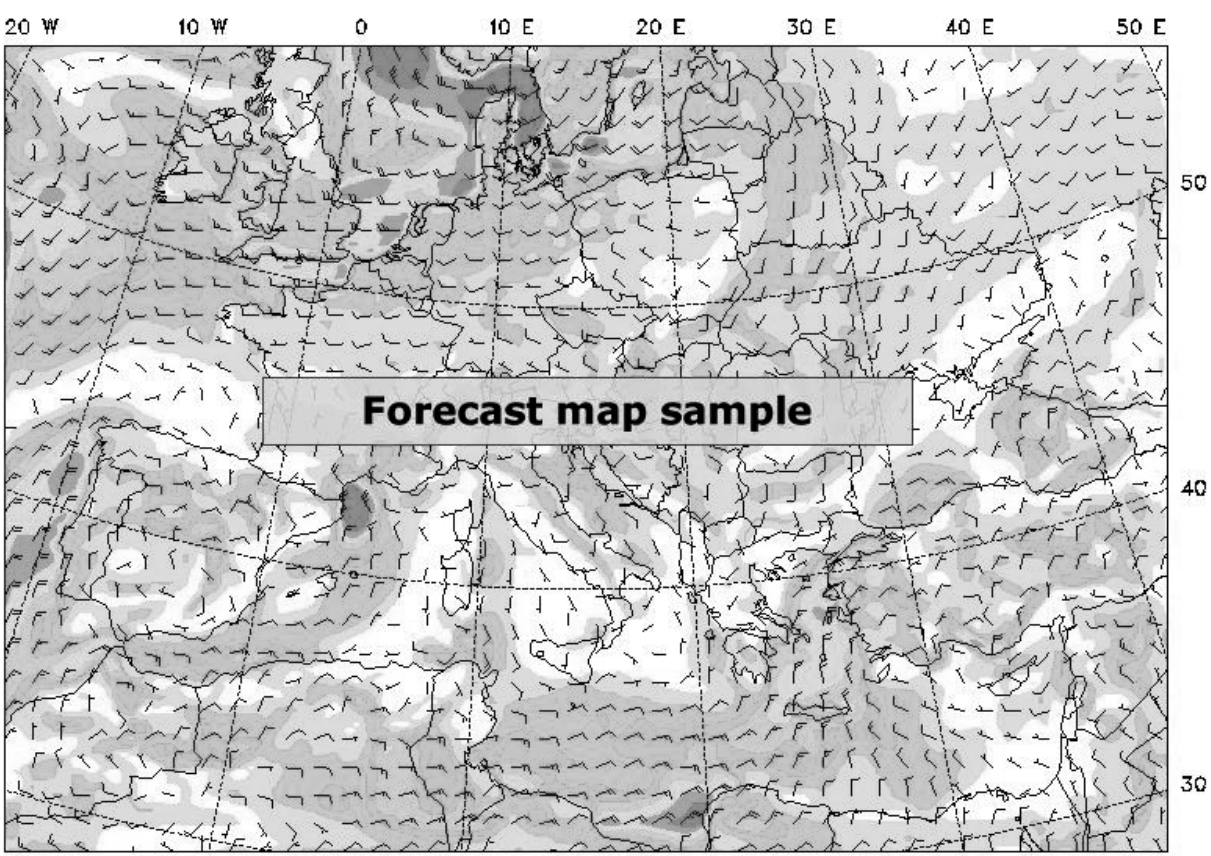

Ejemplo de mapa básico de predicción del 28/01/2011. Fuente: AEMET

Elaborado el 28/01/2011. Válido para el 29/01/2011 de 12 a 24 horas

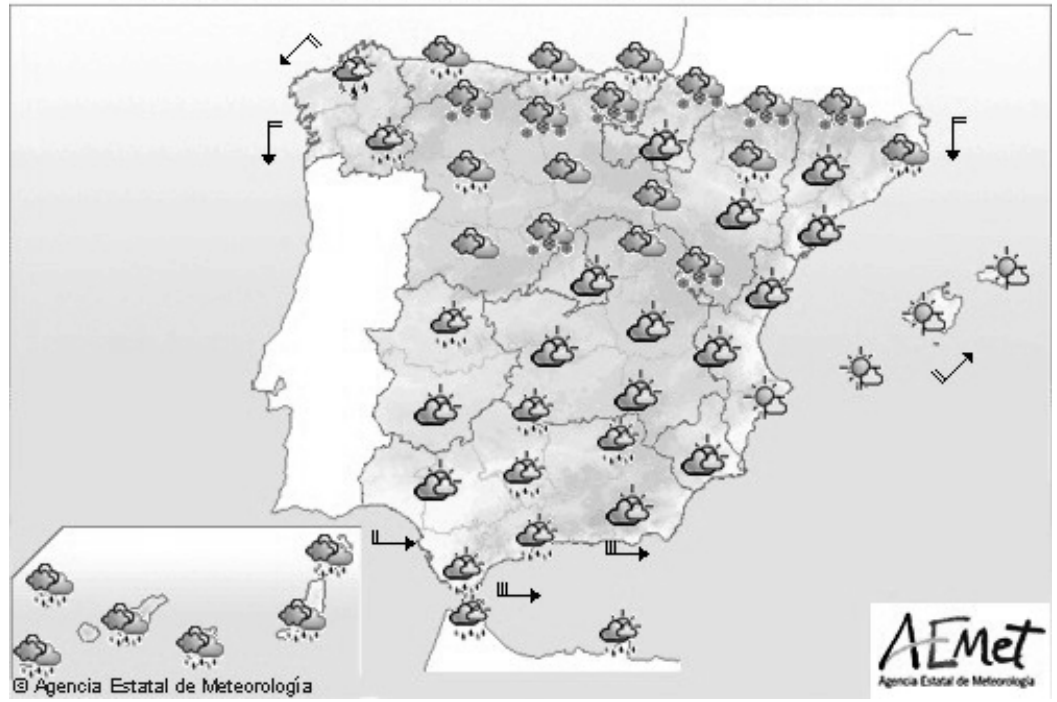




\section{Los sistemas de alertas}

La predicción constituye uno de los ejes principales de la Información Meteorológica. Con el paso del tiempo las herramientas predictivas han mejorado en precisión y fiabilidad y hoy en día esta labor se puede realizar con mayores garantías que en el pasado. Citando a Mariano Medina (1963: 34), nuestro pionero hombre del tiempo, "un pronóstico del tiempo no sale de una bola de cristal. Sale de muchas miles de observaciones hechas simultáneamente cada tres horas, en todas las partes del mundo. Se apoya sobre la labor de los observadores y de otras personas que se ocupan de transmitir, recibir y retransmitir a su vez las citas de miles de mensajes cifrados".

Entre todos los fenómenos meteorológicos que se pueden anticipar, resulta relevante para la sociedad prever y comunicar aquellos que tengan un riesgo potencial para la población. Al igual que sucede en la televisión en los portales meteorológicos se hacen cada vez más necesario informar de este tipo de situaciones, fundamentalmente adversas, conocidas como "Alertas" o, en algunos casos, bajo el término "Avisos".

Entre los portales de nuestro análisis, la gran mayoría -siete- cuentan con un sistema de comunicación de alertas. Las alertas, en el sistema que se sigue habitualmente en España, se dividen en cuatro grados o niveles de riesgo y son representados normalmente cuatro colores: verde, amarillo, naranja y rojo. La alerta verde, indica que no se prevén riesgos de tipo meteorológicos. La alerta amarilla implica un riesgo potencial, que aunque no llegue a afectar a toda la población, sí que puede a determinadas actividades concretas. Con alerta amarilla debemos estar en guardia y bien informados de la evolución atmosférica. La alerta naranja significa un riesgo importante y peligroso. En este caso, se estarían pronosticando fenómenos meteorológicos inusuales -en lo que a su frecuencia de aparición se refiere-, en cuya excepcionalidad reside su peligro. Bajo una de estas situaciones habría que seguir las recomendaciones de las autoridades. Por último, tendíamos el peligro extremo, representado por la alerta roja. Los daños, bajo esta circunstancia, afectarán a áreas extensas del territorio y las medidas adoptadas serán en muchos casos excepcionales.

Esta clasificación es la que se utiliza en portales como www.meteogalicia.es, www.eltiempo.es, www.meteored.com y www.aemet.es. Pero incluso en España son muchos los profesionales que hablan de especificar aún más la categorización de estos colores. El 23 de marzo de 2007, con motivo de la Celebración del Día Meteorológico Mundial, se presentó oficialmente en la localidad madrileña de El Escorial la página web de Meteoalarm (www.meteoalarm.eu), una iniciativa conjunta de la mayoría de Servicios Meteorológicos de Europa, que permite la consulta en tiempo real, a través de Internet, de las distintas alertas meteorológicas para la mayor parte de territorio europeo. El uso del mismo código de colores y la aplicación de criterios comunes de activación de las distintas alertas, hace de este servicio una herramienta de consulta muy valiosa.

En otros portales, de carácter más internacional, se sigue el sistema de representación americano, totalmente distinto al anterior. Los códigos de colores cambian totalmente y así el rojo significa tornado, el verde peligro de inundación, el naranja calor extremo, el gris niebla densa, etcétera. En los portales de www.weather.com y 
www.weatherunderground.com se utiliza este sistema. Es importante tenerlo en cuenta porque puede llevar a errores de interpretación bastante graves.

Respecto a la opinión de los profesionales sobre los mapas y gráficos dicen que son útiles para la comunicación de las alertas, pero no son suficientes. Es necesario acompañar la información visual con un texto en el que se explique, pormenorizadamente, cada uno de los fenómenos que se han previsto y han generado esa alerta. En estos casos, el lenguaje y el estilo, son fundamentales ya que deben ser textos muy cuidados, que informen con la mayor rigurosidad posible, pero sin provocar alarmas innecesarias en la población.

\section{La divulgación de la información}

La Meteorología es una ciencia interdisciplinaria que estudia diferentes fenómenos relacionados con la física, la química, la termodinámica, etcétera. Pero en los últimos tiempos el acercamiento al público general hace necesario que estos fenómenos sean divulgados mediante la interpretación y popularización de estos conocimientos. La función del divulgador -científico o periodista- es fundamental en esta labor, ya que actúa como puente indispensable para establecer la comunicación entre la fuente experta y el ciudadano medio.

De los nueve portales de información meteorológica analizados, solamente uno, www.windguru.com, no cuenta con secciones específicas para la divulgación. Entre los demás nos encontramos que existen portales que apuestan por la divulgación, mientras que otros, más centrados en la predicción, realizan menos esfuerzos en este aspecto.

Entre los más completos sobresale el de www.divulgameteo.es y el de la Agencia Estatal de Meteorología. En ambos aparecen secciones dedicadas exclusivamente a difundir informaciones de eventos, congresos, conferencias, etc. relacionadas con la Meteorología. Y además incluye una recopilación importante de bibliografía y artículos de diferentes autores y fenómenos relacionados con el tema. También acercan al público fenómenos meteorológicos que son actualidad y conviene explicar con mayor profundidad y rigor científico, como ocurrió hace poco tiempo, en febrero de 2010, con la "ciclogénesis explosiva" que afectó a buena parte de la península ibérica y oeste de Francia.

Uno de los mecanismos cada vez más presentes para la divulgación es la utilización de los blogs. Es frecuente que los portales cuenten con enlaces a este tipo de páginas personales en las que un experto en la materia intenta transmitir, desde su experiencia profesional, sus conocimientos meteorológicos al gran público. Uno de los trabajos más reseñables es el que realiza José Antonio Maldonado en www.eltiempo.es. En su blog son muy frecuentes las entradas con información divulgativa, muy bien presentada, tratada y vinculada con la actualidad, que a la vista del número de comentarios que suscitan entre los lectores, se pueden considerar todo un éxito.

Otro de los elementos divulgativos que aparece con frecuencia en los portales analizados es el diccionario de términos meteorológicos. Si bien se constituye como el eslabón más simple y primitivo para la divulgación, no está de más incluirlo -recordemos que el espacio es "casi” gratuito en la Red- para facilitar al usuario la búsqueda de tér- 
minos especializados. Podemos encontrar ejemplos de este tipo de diccionarios en portales como www.meteogalicia.es o www.tutiempo.net.

Tradicionalmente, uno de los instrumentos imprescindibles para la divulgación han sido las revistas especializadas. Con el boom de Internet han emergido publicaciones nuevas de este tipo y otras muchas de las que ya existían se han digitalizado. En el portal de www.meteored.com no se han olvidado de esta interesante opción y han incluido un enlace directo a la revista RAM (revista del aficionado a la meteorología), en la que podemos encontrar abundante material de carácter divulgativo.

En general, se puede afirmar que Internet es un medio ideal por sus características para la divulgación. La distribución del tiempo y el espacio es mucho más libre que en los medios tradicionales -prensa, radio y televisión- y ya no se pueden utilizar las excusas habituales referentes a esta limitación de recursos para obviar o marginar a la divulgación.

\begin{tabular}{|l|c|c|}
\hline \multicolumn{1}{|c|}{ Periodos } & Entradas (Post) & $\mathrm{N}^{\mathrm{o}}$ de comentarios \\
\hline Marzo 2010 & 8 & 262 \\
\hline Febrero 2010 & 6 & 623 \\
\hline Enero 2010 & 7 & 600 \\
\hline TOTAL & 21 & 1485 \\
\hline \multicolumn{2}{|c|}{ Media de comentarios por entrada } & 70,7 \\
\hline \multicolumn{2}{|c|}{ Datos del blog de José Antonio Maldonado } \\
(http://maldonado.eltiempo.es/) en el primer trimestre de 2010 \\
\hline
\end{tabular}

\section{Las posibilidades de interacción de los usuarios}

La pasividad generalizada del lector en la prensa tradicional deja paso a otra forma de concebir el proceso comunicativo a través de la red donde los papeles de emisor y receptor se pueden intercambiar, siendo las barreras cada vez más difusas. Internet supera con diferencia a otros medios de comunicación en cuanto a las numerosas posibilidades de interacción que ofrece a los usuarios Prácticamente en todos los portales de información meteorológica analizados hemos identificado distintos elementos de interacción con los usuarios. La única excepción es la Aemet, que al actuar como centro de referencia estatal constituye un caso muy particular, mucho más cerrado al público en este aspecto.

Uno de los sistemas de interacción más utilizados que hemos detectado en los portales son los foros temáticos. Podemos encontrarlos en www.tutiempo.net, www.windguru.com o www.meteored.com. Son realmente variados en sus contenidos y existen los específicos de climatología, técnicas e instrumentos meteorológicos, naturaleza y medio ambiente, el tiempo local, etcétera. Casi todos permiten a los usuarios interactuar de forma libre y natural, siempre que se cumplan unas normas elementales de respeto implantadas por lo moderadores.

Otro mecanismo muy asentado para la interacción -que se ha consolidado en los últimos años- es la posibilidad de incluir comentarios en las noticias, blogs, fotogra- 
fías, etc. Es una opción sencilla, pero muy interesante, ya que permite tanto la comunicación con otros usuarios como con el autor o autores de la información. Permiten además medir de una forma bastante objetiva el interés que ha despertado entre los lectores un determinado tema y tenerlo en cuenta para futuras publicaciones. Los responsables de los contenidos de los portales de Información Meteorológica no deben en ningún caso desperdiciar este "feedback" pues radiografía con bastante precisión a su público real. Es necesario, en la medida que sea posible, aprovecharlo para mejorar y adaptar sus servicios a las demandas de los usuarios. Cada vez más están surgiendo en la Red organismos dedicados a controlar las audiencias -similares a los existentes en los medios tradicionales- y para la supervivencia de cualquier web se ha convertido en fundamental el crecimiento, fidelización y consolidación de los usuarios para mantenerse en un nivel que pueda considerarse competitivo.

Últimamente, aprovechando el tirón que tiene la fotografía digital, se ha puesto muy de moda que los usuarios tengan la oportunidad de publicar sus fotos relacionadas con la meteorología. Se han incluido secciones de este tipo en www.eltiempo.es, www.tutiempo.net o www.weatherunderground.com. Es un sistema que potencia la interacción visual y que además abre una puerta a estos portales a todos los aficionados a la fotografía. Ante determinados fenómenos meteorológicos, fugaces y muy localizados, la aportación de documentos audiovisuales de los usuarios que fueron testigos del suceso se ha convertido en algo muy importante para los medios, no sólo en Internet. Es muy habitual, en los últimos tiempos, ver en la televisión grabaciones de videoaficionados que lograron captar una impresionante tormenta, una riada, un tornado, etcétera.

Pocos portales meteorológicos se arriesgan, de momento, a ofrecer sistemas de interacción con los usuarios realmente innovadores. Sólo en www.weather.com, podemos encontrar opciones de interacción que de momento en nuestro país son poco frecuentes. Por ejemplo, ofrece la posibilidad de chatear en vivo con meteorólogos o realizar un instructivo recorrido por un estudio virtual. No obstante, hay que remarcar que estas opciones solamente aparecen en la versión internacional del sitio en inglés. Si accedemos a la versión traducida al español únicamente tendremos disponibles algunas opciones básicas del portal. Es probable que en el futuro se vayan incorporando todas las secciones en español pero mientras tanto hay que tener en cuenta estas limitaciones. Hoy por hoy, el idioma de la red sigue siendo el inglés y aunque poco a poco se van incorporando gran cantidad de contenidos en otros lenguajes todavía es necesario manejarlo como lenguaje referencial en las búsquedas.

\section{Conclusiones}

- Entre los objetivos principales de los medios de comunicación actuales está el proporcionan una respuesta informativa a las preocupaciones cotidianas de los usuarios. En la actualidad son varias las informaciones que ocupan las primeras planas de los medios de comunicación y una de las que cada día alcanza un mayor protagonismo es la Información Meteorológica.

- La frecuencia y aparición de fenómenos meteorológicos adversos se traduce en la actualidad en el incremento e interés de la demanda de Información Meteorológica 
por parte de públicos muy diversos. El $88 \%$ de los encuestados en este estudio afirman que consultan y utilizan este tipo de información. Lo que ha provocado una mayor presencia de esta información en los medios adaptada a las prestaciones y las necesidades que reclaman los nuevos usuarios.

- Los medios preferidos por los ciudadanos para consultar en la actualidad la información meteorológica son Televisión e Internet. De nuestro estudio se desprende que un $42 \%$ de los encuestados dicen consultar la Información Meteorológica a través de los distintos canales de televisión y otro $42 \%$ la consultan por Internet. La prensa escrita sólo es elegida por un $8 \%$ de los encuestados y el teléfono móvil, de momento, tiene una presencia escasa que alcanza solo $2 \%$. De este $42 \%$ de los usuarios que habitualmente consultan la Información Meteorológica en la Web más de la mitad, el 51\%, optan por consultarla en portales especializados en Información Meteorológica. Otro 23\% de ellos se inclinan por la prensa digital y sólo el $20 \%$ de los encuestados optan por los portales de contenidos generalistas.

- Los portales especializados en Información Meteorológica cubren muchas de las carencias informativas detectadas en nuestro estudio en el apartado de la prensa digital. Su finalidad es proporcionar una información útil y práctica con el objetivo de ofrecer una información más completa, rica en fuentes y mejor organizada. Para ello destinan más recursos, como los blogs, para la divulgación de los contenidos científicos. Incluyen mecanismos para la participación de la audiencia e insertan otros elementos útiles como los servicios de alertas.

- El portal más referenciado como fuente, el que mayor número de usuarios recibe, el que más interés presta al servicio de alertas y a los servicios de divulgación meteorológica es el de la AEMET (Asociación Estatal de Meteorología). En el resto de los portales (www.meteogalicia.es, www.eltiempo.es,, www.tutiempo.net, www.windguru.com, www.meteored.com, www.weather.com, www.weatherunderground.com) observamos que se esfuerzan en potenciar algunos elementos como la especialización de los contenidos, el idioma elegido, el diseño o la figura del experto de prestigio para diferenciarse del resto. El portal www.eltiempo.es, establece su elemento diferenciador en potenciar la sencillez en el diseño y en la navegación, además de apoyarse en la figura del reconocido meteorólogo José Antonio Maldonado. Otros como www.windguru.com utilizan su especialización en informar del viento. En www.meteogalicia.es su punto fuerte es la especialización en todos los temas gallegos. En www.meteored.com destaca su conexión con la revista RAM (Revista del Aficionado a la Meteorología) que le permite estar al día y al momento con los últimos artículos, reportajes, noticias, etc.

- En todas aquellas webs dedicadas al deporte, ocio y actividades al aire libre se comprueba que los portales especializados en Información Meteorológica se han convertido en un elemento imprescindible. Proporcionan una información útil y de consumo rápido para aquellos usuarios-internautas que buscan en la Red información completa para su uso y que se adapte a sus intereses. Esta colaboración entre los portales y las webs conduce a una popularización de los primeros porque muchos usuarios entran por primera vez a estos portales a través de estas webs. 
- Son los portales americanos los más habituados a incluir unos sistemas de búsqueda más potentes y precisos. Con esto se desprende que están específicamente diseñados para usuarios más bien experimentados y que precisan de un uso más intensivo de las herramientas de búsqueda.

\section{Referencias Bibliográficas}

BINKLEY, Mark (1999): Television weathercaster. Encyclopedia of Television News. Phoenix, Oryx Press, Michael Murphy Ed., pp. 276-277.

MALDONADO, José Antonio: Blog: http://maldonado.eltiempo.es/

MEDINA, Mariano (1963): El tiempo es noticia. Madrid, Ediciones Cid.

VIÑAS, J. Miguel (2008): "La divulgación de la Meteorología en la radio española" en: http://www.divulgameteo.es/amplia_aula.asp?id=68 [fecha de consulta: $12 \mathrm{de}$ enero de 2011]

WEBS: www.meteogalicia.es. www.eltiempo.es. www-tutiempo.net. www.windguru .com. www.meteored.com. www.weather.com. www.divulgameteo.es. www.weatherunderground.com. www.aemet.es. 